
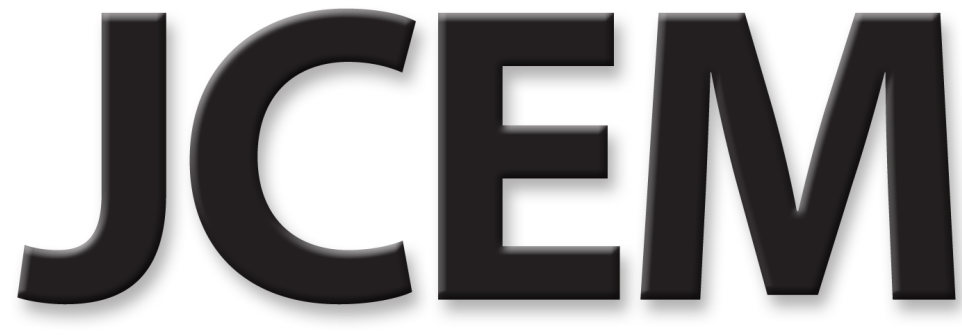

\title{
Mutation Analysis of the MEN1 Gene in Multiple Endocrine Neoplasia Type 1, Familial Acromegaly and Familial Isolated Hyperparathyroidism
}

B. T. Teh, S. Kytölä, F. Farnebo, L. Bergman, F. K. Wong, G. Weber, N. Hayward, C. Larsson, B. Skogseid, A. Beckers, C. Phelan, M. Edwards, M. Epstein, F. Alford, D. Hurley, S. Grimmond, G. Silins, M. Walters, C. Stewart, J. Cardinal, S.

Khodaei, F. Parente, L. Tranebjærg, R. Jorde, J. Menon, A. Khir, T. T. Tan, S. P. Chan, A. Zaini, B. A. K. Khalid, K. Sandelin,

N. Thompson, M.-L. Brandi, M. Warth, J. Stock, J. Leisti, D. Cameron, J. J. Shepherd, K. Öberg, M. Nordenskjöld and P. Salmela

J. Clin. Endocrinol. Metab. 1998 83: 2621-2626, doi: 10.1210/jc.83.8.2621

To subscribe to Journal of Clinical Endocrinology \& Metabolism or any of the other journals published by The Endocrine Society please go to: http://jcem.endojournals.org//subscriptions/
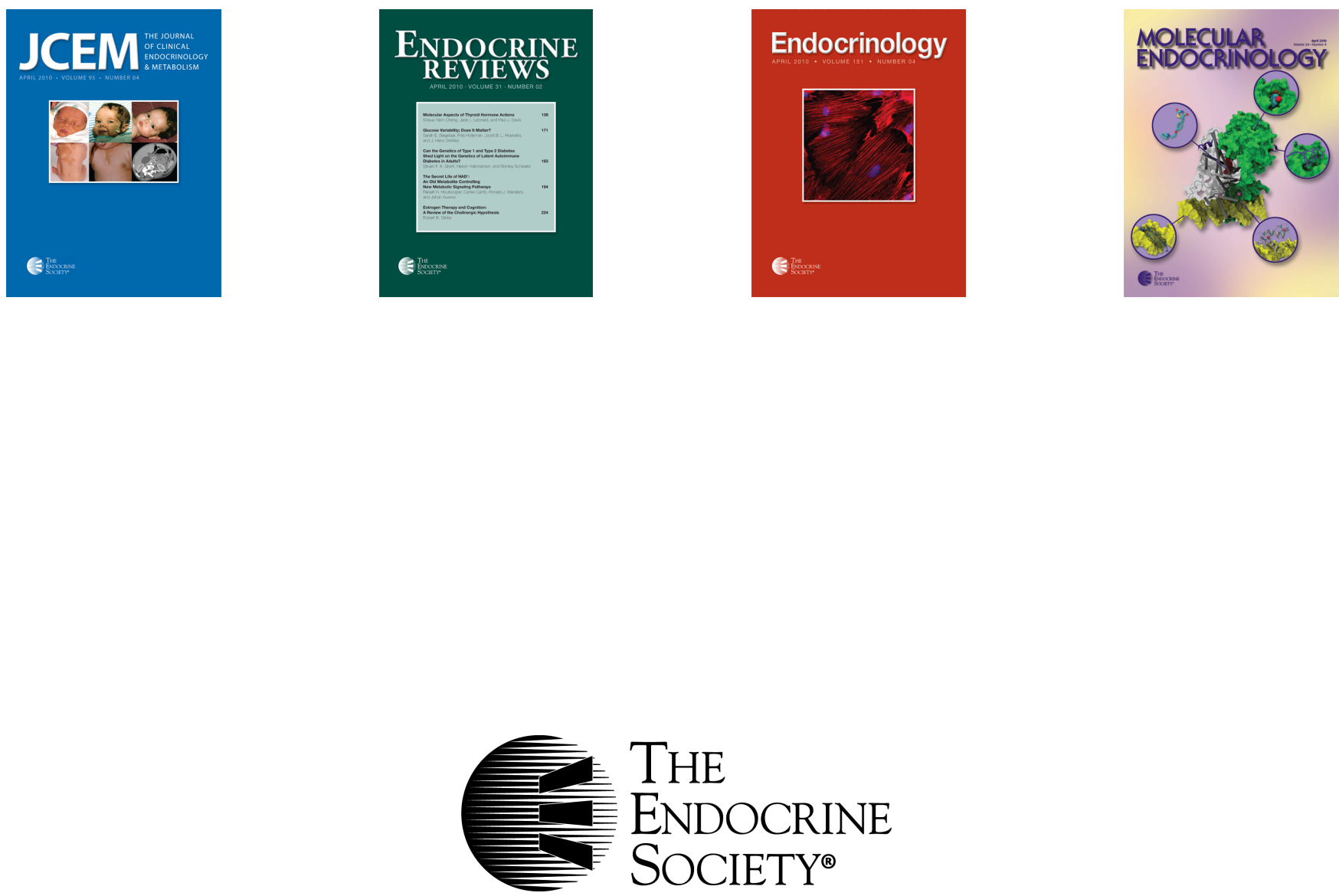


\title{
Mutation Analysis of the MEN1 Gene in Multiple Endocrine Neoplasia Type 1, Familial Acromegaly and Familial Isolated Hyperparathyroidism*
}

\author{
MUTATION ANALYSIS GROUP: B. T. TEH, S. KYTÖLÄ, F. FARNEBO, L. BERGMAN,
} F. K. WONG, G. WEBER, N. HAYWARD, AND C. LARSSON

CLINICAL DIAGNOSIS GROUP: B. SKOGSEID, A. BECKERS, C. PHELAN, M. EDWARDS, M. EPSTEIN, F. ALFORD, D. HURLEY, S. GRIMMOND, G. SILINS, M. WALTERS, C. STEWART, J. CARDINAL, S. KHODAEI, F. PARENTE, L. TRANEBJÆRG, R. JORDE, J. MENON, A. KHIR, T. T. TAN, S. P. CHAN, A. ZAINI, B. A. K. KHALID, K. SANDELIN, N. THOMPSON, M.-L. BRANDI, M. WARTH, J. STOCK, J. LEISTI, D. CAMERON, J. J. SHEPHERD, K. ÖBERG, M. NORDENSKJÖLD, AND P. SALMELA

Endocrine Tumor (B.T.T., S.Ky., F.F., F.K.W., C.L., C.P.) and Clinical Genetics Units (G.W., S.Kh., P.F., and M.N.), Department of Molecular Medicine, Karolinska Hospital, Sweden; Departments of Clinical Genetics (S.Ky., J.L.) and Internal Medicine (P.S.), Oulu University Hospital, Finland; Queensland Institute of Medical Research (L.B., N.H., G.S., M.W., C.S.), Princess Alexandra Hospital (J.C., D.C.), Hunter Area Health Service (M.Ed.); Princeton Medical Centre Hamilton (M.Ep.); Royal Perth Hospital (D.H.); St. Vincents Hospital (F.A.); Royal Hobart Hospital (J.J.S.), Australia; Department of Internal Medicine, Uppsala University Hospital, Sweden (B.S., K.Ö.); Department of Endocrinology, Sart Tilman University Hopital, Liege, Belgium (A.B.); Departments of Medical Genetics (L.T.) and Internal Medicine (R.J.), University Hospital of Tromsø, Norway; Department of Medicine (J.M.), Queen Elisabeth Hospital, Kuta Kinabalu, Sabah, Malaysia; Faculty of Medicine, University of Malaya (A.K., S.P.C., A.Z.), University Kebangsaan Malaysia (T.T.T., B.A.K.K) Kuala Lumpur, Malaysia; University of Michigan Hospital (N.T.), Ann Arbor, Michigan; Department of Clinical Physiopathology (M.-L.B.), University of Florence, Italy; Endocrinology, Memorial Hospital (M.W., J.S.), Worcester, Massachussets

\begin{abstract}
Multiple endocrine neoplasia type 1 (MEN 1) is an autosomal dominant disease characterized by neoplasia of the parathyroid glands, the endocrine pancreas, and the anterior pituitary gland. In addition, families with isolated endocrine neoplasia, notably familial isolated hyperparathyroidism (FIHP) and familial acromegaly, have also been reported. However, whether these families constitute MEN 1 variants or separate entities remains speculative as the genetic bases for these diseases are unclear. The gene for MEN 1 has recently been cloned and characterized. Using single strand conformation analysis (SSCA) and sequencing, we performed mutation analysis in: a) a total of 55 MEN 1 families from 7 countries, b) 13 isolated MEN 1 cases without family history of the disease, c) 8 acromegaly families, and d) 4 FIHP families. Mutations were identified in 27 MEN 1
\end{abstract}

families and 9 isolated cases. The 22 different mutations spread across most of the 9 translated exons and included frameshift (11), nonsense (6), splice (2), missense mutations (2), and in-frame deletions (1). Among the 19 Finnish MEN 1 probands, a 1466del12 mutation was identified in 6 families with identical 11q 13 haplotypes and in 2 isolated cases indicating a common founder. One frameshift mutation caused by 359del4 (GTCT) was found in 1 isolated case and 4 kindreds of different origin and haplotypes; this mutation therefore represents a common "warm" spot in the MEN1 gene. By analyzing the DNA of the parents of an isolated case one mutation was confirmed to be de novo. No mutation was found in any of the acromegaly and small FIHP families, suggesting that genetic defects other than the MEN1 gene might be involved and that additional such families need to be analyzed. (J Clin Endocrinol Metab 83: 2621-2626, 1998)
$\mathrm{M}$ ULTIPLE endocrine neoplasia type 1 (MEN 1)(OMIM*131100) is one of the familial cancer syndromes transmitted as an autosomal dominant trait with

Received December 16, 1997. Revision received May 28, 1998. Accepted June 1, 1998.

Address all correspondence and requests for reprints to: Catharina Larsson, M.D., Ph.D., Endocrine Tumor Unit, Department of Molecular Medicine, Karolinska Hospital CMM L8:01, S-171 76 Stockholm, Sweden. E-mail: Catharina.Larsson@cmm.ki.se.

* This work was supported by the Swedish Cancer Foundation, the Torsten and Ragnar Söderberg Memory Foundations, The Wenner-Gren Center Foundation, the Cancer Society of Stockholm (96-113), the King Gustaf V Jubilee Fund (97:540, 97:528), Queensland Cancer Fund and the Australian National Health and Medical Research Council. over 95\% penetrance and an equal sex distribution. It is characterized by neoplasia of the parathyroids $(90-97 \%$ of patients), the endocrine pancreas $(30-80 \%)$, and the anterior pituitary (15-50\%) (1). The patients may have only one type of gland involved or any combination, but in addition may have other less frequently associated features such as lipomas, carcinoids, and adrenocortical neoplasia. Although the majority of known MEN 1 families are of Caucasian origin, MEN 1 families of other ethnic groups have been described $(2,3)$. Recently, the MEN1 gene, which was mapped to chromosomal region 11q13 (4), was identified by positional cloning $(5,6)$. It contains 1 untranslated exon and 9 coding exons that encode a 610-amino acid protein. As it has no homology 
to previously known proteins, its function remains unknown. Mutation analysis in MEN 1 patients identified mutations in all of the 9 coding exons, but no genotype-phenotype correlation was established (7).

A number of reported kindreds with familial endocrine disorder, notably familial isolated hyperparathyroidism (FIHP) and familial pituitary tumors, had been considered as variants of MEN 1. Some of these families were found to be linked to the MEN1 locus, while some were excluded. To date, all FIHP families tested genetically were assigned to the loci of either MEN 1 (8) or the hyperparathyroidism-jawtumor syndrome (HP-JT), which was mapped to chromosome 1q21-q32 $(9,10)$. In the case of familial pituitary tumors, the majority of reported families were mainly characterized by familial acromegaly. In these families the mode of transmission was considered as autosomal dominant, and reduced penetrance was frequently found. In addition, the families were usually small compared with those of classical MEN 1, and a number of them also had additional endocrine lesions $(11,12)$. To date, linkage to MEN1 has been excluded in two kindreds but no new locus has been assigned $(11,12)$. However, in one Japanese family with 3 affected members, linkage to MEN1 could not be excluded, and loss of heterozygosity of the "wild-type" alleles was found in two tumors from the two brothers (13).

The present mutation screening was undertaken to further elucidate the repertoire of mutations in MEN 1 patients and its possible role in FIHP and familial acromegaly.

\section{Subjects, Materials, and Methods}

\section{Families}

Informed consent was obtained from all patients, and the study was approved by the local Ethical Committees of each participating hospital. The diagnosis of MEN 1 was based on the finding of neoplasia in 2 or more principal MEN 1-related glands i.e. parathyroid, endocrine pancreas, and anterior pituitary. In familial MEN 1, 1 member fulfilling the criteria for MEN 1 and 1 first degree relative with 1 feature had to be found in a kindred. A de novo germline mutation was considered in an individual with clinical features of MEN 1, who had a negative family history including exclusion of the disease in both parents. We performed mutation analysis on a total of 55 MEN 1 families from 7 countries: 16 Finnish, 19 Swedish, 13 Australian, 2 Malaysian (Chinese/Mongolian descent), 3 North American, 1 Italian, and 1 Iranian. The results from 2 of the families (Swe 1-40 and Swe 1-43) have been published previously (6). In addition, we also studied 13 isolated cases with no family history of MEN 1.

Four FIHP families in which linkage to the MEN1 gene could not be excluded by haplotyping or lod score analysis, were included in the present studies. Clinically, these were families with two or more members with primary hyperparathyroidism: one family with four affected cases including a pair of identical twins, one with three cases, and two with two cases. In all cases, multiglandular disease was found, and familial benign hypocalciuric hypercalcemia was excluded by biochemical screening including urine calcium. Families that were linked to the HPT-JT (HRPT2) locus in 1q (10) were not included in the analysis.

The eight acromegaly families comprised seven acromegaly-only families and one family with two cases of acromegaly, one primary hyperparathyroidism, and one prolactinoma (12). One of the acromegaly-only families was the largest reported family, with five affected cases (14). Five other families have not been reported: one with three affected (see Fig. 3 below) and four with two affected members. Family members from these families had been investigated vigorously for MEN 1 and, except for growth-hormone secreting pituitary tumors, no evidence of other endocrinopathies could be found.

\section{Single-Strand Conformation Analysis (SSCA)}

Genomic DNA was extracted from peripheral blood samples using standard methods. The 9 translated exons of the gene were amplified as 15 different fragments of 200-300 bp each, as previously described (6). Genomic DNA (50 ng) was amplified using standard PCR conditions in $50 \mathrm{~mm} \mathrm{KCl}, 10 \mathrm{~mm}$ Tris- $\mathrm{HCl}$, pH 9.0, $1.5 \mathrm{~mm} \mathrm{MgCl}_{2}$ (Promega, Madison, WI), $0.2 \mathrm{~mm}$ dTTP, dCTP, and dGTP, $0.05 \mathrm{~mm}$ dATP, and $\left[\alpha^{-}{ }^{32} \mathrm{P}\right]-\mathrm{dATP}$ (NEN, Boston, MA) at $1 \mu \mathrm{Ci} /$ reaction and $2 \mathrm{U}$ Taq DNA polymerase (Promega) in a final volume of $15 \mu \mathrm{L}$. Thermocycling conditions consisted of 30 cycles of $1 \mathrm{~min}$ at $94 \mathrm{C}, 1 \mathrm{~min}$ at $62 \mathrm{C}$, and $1 \mathrm{~min}$ at $72 \mathrm{C}$, followed by one cycle of $5 \mathrm{~min}$ extension at $72 \mathrm{C}$. The PCR products were then electrophoresed in 25\% MDE (FMC, ME) gels at room temperature for $12 \mathrm{~h}$ at $6-8 \mathrm{~W}$. Gels were dried before autoradiography was carried out.

\section{Direct DNA sequencing}

Three acromegaly families were fully sequenced. The rest were studied by SSCA followed by sequencing of the shifted bands. All SSCA shifted bands were excised from the MDE gel and placed in $50 \mu \mathrm{L}$ of $\mathrm{H}_{2} \mathrm{O}$ at $37 \mathrm{C}$ for $1 \mathrm{~h}$. A $5 \mu \mathrm{L}$ aliquot of this solution was then amplified in a $50 \mu \mathrm{L}$ reaction with the following components: $50 \mathrm{~mm} \mathrm{KCl}, 10 \mathrm{~mm}$ Tris- $\mathrm{HCl}$, pH 9.0, 1.5 mm $\mathrm{MgCl}_{2}$ (Promega), $0.2 \mathrm{~mm}$ dTTP, dCTP, dGTP, and dATP, and $1.5 \mathrm{U}$ of Taq DNA polymerase (Promega). The purified PCR products were sequenced from both strands. For sequence reactions, one of the PCR primers was biotinylated at the $5^{\prime}$ end. Solid phase sequence reactions with ${ }^{35} \mathrm{~S}^{\prime}$-labeled dATP were performed using Dynabeads (Dynal, Chantilly, VA) and Sequenase (USB, Cleveland, $\mathrm{OH}$ ) according to the manufacturer's manuals, followed by Terminal Deoxynucleotidyl Transferase (Boehringer Mannheim, Indianapolis, IN) treatment for 15 minutes with the addition of $0.2 \mathrm{~mm}$ dNTP's. Sequence reactions were then run on $6 \%$ denaturing polyacrylamide gels and autoradiographed overnight. Confirmation of mutation was carried out in the families to demonstrate segregation of the mutation with the disease. In cases where the mutation created or eliminated a restriction site, restriction cleavage was carried out in the family members. In the cases where the mutation did not affect a restriction site, the mutation was sequenced in affected and unaffected family members. Missense mutations were sought in 100 unaffected individuals.

Genotyping and linkage analysis. Five polymorphic microsatellite markers close to and flanking MEN1 were selected (15): D11S480, PYGM, D11S449, D11S4155, and D11S913. The members of the Norwegian pedigree were also genotyped with two additional markers D1S1679 and D18S976 to confirm parenthood. PCR reactions were performed in a total volume of $10 \mu \mathrm{L}$ containing 50-100 ng of genomic DNA, $50 \mathrm{~mm} \mathrm{KCl}, 10$ $\mathrm{mm}$ Tris- $\mathrm{HCl}$ ( $\mathrm{pH} 8.3), 1.5 \mathrm{~mm} \mathrm{MgCl} 2,125 \mu \mathrm{M}$ of each dNTP, 2 pmol of each oligodeoxynucleotide primer (one of which was end-labeled with $\left.\left[\gamma^{32} \mathrm{P}\right]-\mathrm{dATP}\right)$, and $0.2 \mathrm{U}$ DNA polymerase (Dynazyme, Finnzyme Oy, Finland). Samples were amplified using a hot-start of $5 \mathrm{~min}$ at $94 \mathrm{C}$, followed by 25 cycles of denaturing at $94 \mathrm{C}$ for $30 \mathrm{sec}$, annealing at 55 $\mathrm{C}$ for $30 \mathrm{sec}$, and elongation at $72 \mathrm{C}$ for $30 \mathrm{sec}$, and a final elongation step at $72 \mathrm{C}$ for $7 \mathrm{~min}$. Polyacrylamide gel electrophoresis was carried out on the PCR products followed by either autoradiography or Bio-imaging analysis (Bas 1000, Fuji, Japan). Haplotypes were then constructed.

Two point lod scores were calculated for the acromegly family of Kadazan origin using LINKAGE package 5.1 (15a). Using a conservative approach, cases III-1, 2, and 6 were labeled as affected, while all unaffected cases were considered as unknown. Familial acromegaly was modeled as a rare autosomal dominant disease with a reduced penetrance $(50 \%)$. Allele frequencies were set at equal levels.

\section{Results}

A total of 22 different mutations (Figs. 1 and 2) were identified in 27 MEN 1 families (51\%) and 9 isolated cases $(69 \%)$. These different mutations consisted of 11 frameshift, 6 nonsense, 2 splicing, 2 missense mutations, and 1 in-frame deletion (Table 1). Five mutations occured in more than 1 proband: 359del4 in 5, 738del4 in 2, W341X in 2, 1466del12 in 8 , and 1657insC in 2. 


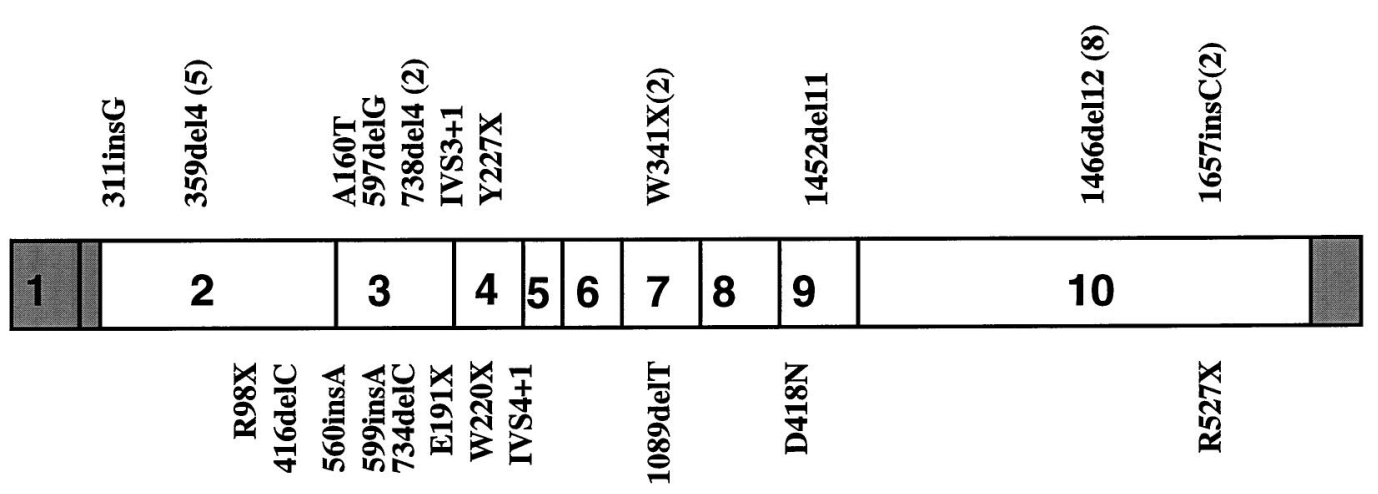

FIG. 1. Diagramatic representation of the mutations found in the MEN1 gene. The first exon is not transcribed. The numbers in brackets represent the number of unrelated MEN 1 patients with the same mutation.

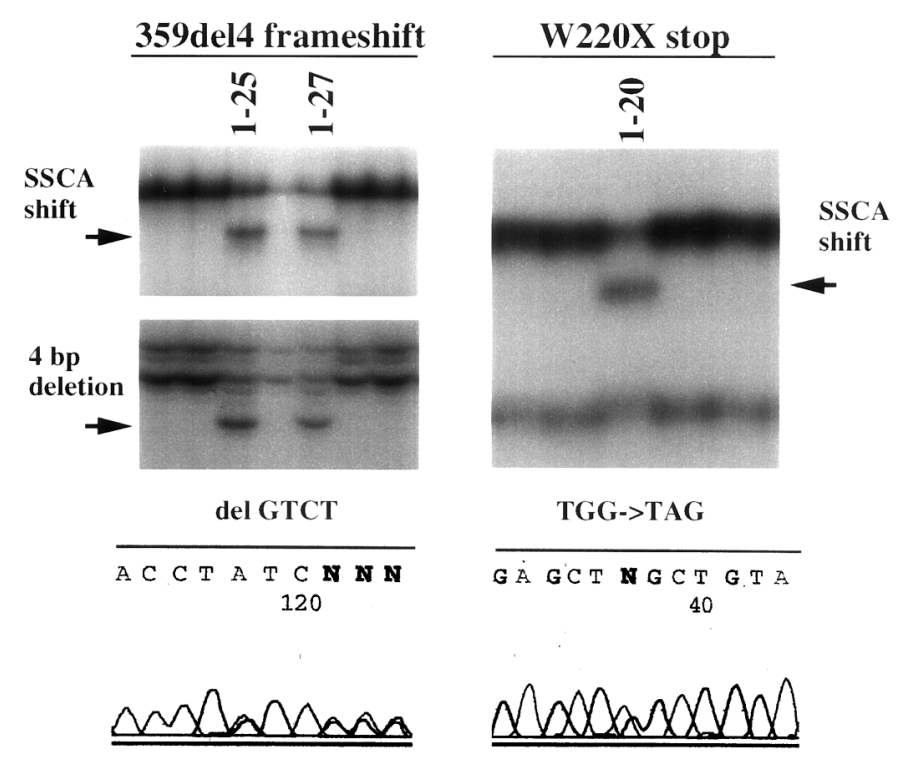

FIG. 2. Examples of MEN1 mutation detection in three familial MEN 1 cases. Left: SSCA shifts detected in exon 2 in families 1-25 and 1-27 are shown to be a $4 \mathrm{bp}$ deletion by separating the PCR products in sequencing gels, and the mutation is then identified as a 359del4 framshift by direct sequencing. To the right is shown an SSCA shift in exon 3 detected in family $1-20$ and confirmed to be a nonsense W220X mutation by direct sequencing.

Five common polymorphisms were also detected in 12 MEN 1 families: S145S, R171Q, G214G, D418D, and A541T. In the 19 Finnish MEN 1 probands, only 2 mutations were found: D418N in 1 family and 1466del12 in 6 families and 2 isolated cases. The 6 families shared the same MEN 1-linked marker haplotypes (data not shown). No mutation was found in 10 other Finnish families. One Norwegian isolated MEN 1 case without family history of the disease had primary hyperparathyroidism, gastrinoma, and benign adrenocortical tumors, and showed a 597delG mutation (Fig. 3). This mutation was not present in either of his parents nor in his sister, who were all normal on clinical and biochemical examination. Parenthood was confirmed by typing of $6 \mathrm{mi}-$ crosatellite markers from chromosomes 1, 11, and 18. The results for the 4 markers in $11 q 13$ are shown in Fig. 3 . The MEN1 mutation was transmitted to 2 of the children, comfirming that the patient carries a de novo germline MEN1 mutation. These 2 children are in their teens, and clinical evidence of primary hyperparathyroidism was subsequently found in the older sister (III-2 Fig. 3), while the younger sister is still disease free.

No mutation was identified in any of the four FIHP and eight acromegaly families. One acromegaly family in which MEN 1 could not be excluded by haplotyping or linkage analysis is shown in Fig. 4. Maxiumum lod scores of 0.86 at $\theta=0.0$ were obtained with the markers PYGM and D11S4155. However no MEN1 mutation was found in this family neither by SSCA screening or full sequencing.

\section{Discussion}

Overall, we only detected mutations in about $55 \%$ of all cases, compared with a previous report which detected over $90 \%$ of mutations in their families by using dideoxy finger printing (ddf) (7). This discrepancy could be related to the difference in sensitivity of both methods. We employed the more common method of SSCA, which usually has a detection rate of approximately 50-70\%. Also, the disrepancy in the present study might reflect the difference in patient material. It is possible that some of the mutations might occur in untranscribed or regulatory regions.

We identified 22 different mutations in 27 MEN 1 families and 9 isolated cases. In agreement with previous reports, the majority of these mutations were frameshift or nonsense, which would eliminate the functions of one copy of the gene. These results, together with the findings of inactivating mutations in endocrine tumors that showed LOH of 11q13 (16, 17), support Knudson's two-hits mutation theory of a tumor suppressor gene (18). In the future, it will be interesting to see how the function of the gene, which will come to light in due course, fits in with this theory. The present study also extends the spectrum of mutations in the MEN1 gene, which spread across most of the translated exons. This wide spectrum of mutations, together with the vast intra- and interfamilial phenotypic variations, implies difficulties in genotype-phenotype correlation. Recently, we identified a number of families with clusterings of thymic carcinoids, uncommon but malignant tumors of which a quarter were associated with MEN 1 $(19,20)$. Mutation analysis in these families confirmed different germ-line mutations in different exons of the gene (20). In the study of the kindreds with the prolactinoma variant, which is considered a distinct MEN 1 phenotype $\mathrm{MEN1}_{\text {Burin }}$, three different genotypes were found. Two mu- 
TABLE 1. MEN1 mutations in 27 familial and 9 isolated MEN 1 cases

\begin{tabular}{|c|c|c|c|c|}
\hline Pedigree & Country & Exon & Mutation & Amino acid \\
\hline $2-16 \#$ & Sweden & 2 & 311insG & Frameshift \\
\hline $1-25$ & Malaysia & 2 & 359del4(GTCT) & Frameshift, 32 missense aa stop \\
\hline $2-45 \#$ & Australia & 2 & 359del4(GTCT) & Frameshift, 32 missense aa stop \\
\hline $1-27$ & Australia & 2 & 359del4(GTCT) & Frameshift, 32 missense aa stop \\
\hline $1-42$ & Sweden & 2 & 359del4(GTCT) & Frameshift, 32 missense aa stop \\
\hline $1-43$ & Sweden & 2 & 359del4(GTCT) & Frameshift, 32 missense aa stop \\
\hline $1-40$ & Sweden & 2 & R98X & Stop \\
\hline $2-6$ \# & USA & 2 & 416delC & Frameshift \\
\hline $2-26 \#$ & Sweden & 3 & 560insA & Frameshift \\
\hline $2-24$ & Sweden & 3 & A160T & Missense, ala to thr \\
\hline $1-48$ \# & Norway & 3 & 597delG & Frameshift \\
\hline $1-29$ & Australia & 3 & 599insA & Frameshift \\
\hline $1-31$ & Australia & 3 & E191X & Stop \\
\hline $2-18 \#$ & Sweden & 3 & 734delC & Frameshift \\
\hline $2-34$ & Italy & 3 & 738del4(ACAG) & Frameshift \\
\hline $2-20 \#$ & Sweden & 3 & 738del4(ACAG) & Frameshift \\
\hline $1-19$ & Australia & 3 & IVS3 $+1(\mathrm{G}-\mathrm{T})$ & Splicing \\
\hline $1-20$ & Australia & 4 & W220X & Stop \\
\hline $1-44$ & Sweden & 4 & Y227X & Stop \\
\hline $1-35$ & Australia & 4 & IVS4 $+1(G-T)$ & Splicing \\
\hline $2-36$ & Sweden & 7 & 1089 delT & Frameshift \\
\hline $1-46$ & Sweden & 7 & W341X & Stop \\
\hline $1-50$ & Sweden & 7 & W341X & Stop \\
\hline $1-8$ & Finland & 9 & $\mathrm{D} 418 \mathrm{~N}$ & Missense, asp to asn \\
\hline $1-30$ & Australia & 9 & 1452del11(GAGGGACAG/GT) & Frameshift \\
\hline $1-3$ & Finland & 10 & 1466del12(GCAGAAGGTGCG) & Loss of 3 aa \\
\hline $1-6$ & Finland & 10 & 1466del12(GCAGAAGGTGCG) & Loss of 3 aa \\
\hline $1-7$ & Finland & 10 & 1466del12(GCAGAAGGTGCG) & Loss of 3 aa \\
\hline $1-11 \#$ & Finland & 10 & 1466del12(GCAGAAGGTGCG) & Loss of 3 aa \\
\hline $1-12$ & Finland & 10 & 1466del12(GCAGAAGGTGCG) & Loss of 3 aa \\
\hline $1-16$ \# & Finland & 10 & 1466del12(GCAGAAGGTGCG) & Loss of 3 aa \\
\hline $1-17$ & Finland & 10 & 1466del12(GCAGAAGGTGCG) & Loss of 3 aa \\
\hline $1-51$ & Finland & 10 & 1466del12(GCAGAAGGTGCG) & Loss of 3 aa \\
\hline $1-26$ & Australia & 10 & $1657 \mathrm{ins}$ C & Frameshift \\
\hline $1-34$ & Australia & 10 & 1657insC & Frameshift \\
\hline $2-30$ & Sweden & 10 & R527X & Stop \\
\hline
\end{tabular}

\#, Isolated case; aa, amino acid.

tations were in different exons and one not detected, thus excluding any genotype-phenotype correlation (7).

Mutations were also found in 9 of 13 isolated cases in which no family history of MEN 1 could be found. This rate of mutation detection made mutation analysis of the MEN1 gene worthwhile in isolated cases. All isolated cases had 2 or more of the MEN 1-related features. In one case, in which the DNA of both parents were available, we confirmed that it was a de novo mutation (Fig. 2). In addition, we also found a common mutation, 359del 4 (GTCT) in 5 probands: 2 Swedish, 1 Australian, and 1 Malaysian family of Chinese origin, and 1 isolated case from Australia. Except the 2 Swedish families, which shared the same 11q13 haplotype, the others were found to have different haplotypes. This mutation was also reported in a French family (6), suggesting the existence of a mutation "warm spot". Clinically, there was no salient feature in these families that distinguished them from other MEN 1 families.

Founder effect is well-known in a number of hereditary diseases found in isolated populations. In the Finnish population, which is only $80-100$ generations old, some 30 diseases have been reported to be more prevalent than in other populations (21), and identification of some of these genes has shown the existence of common founders (22). As MEN 1 is not more prevalent in the Finnish population, it is ex-

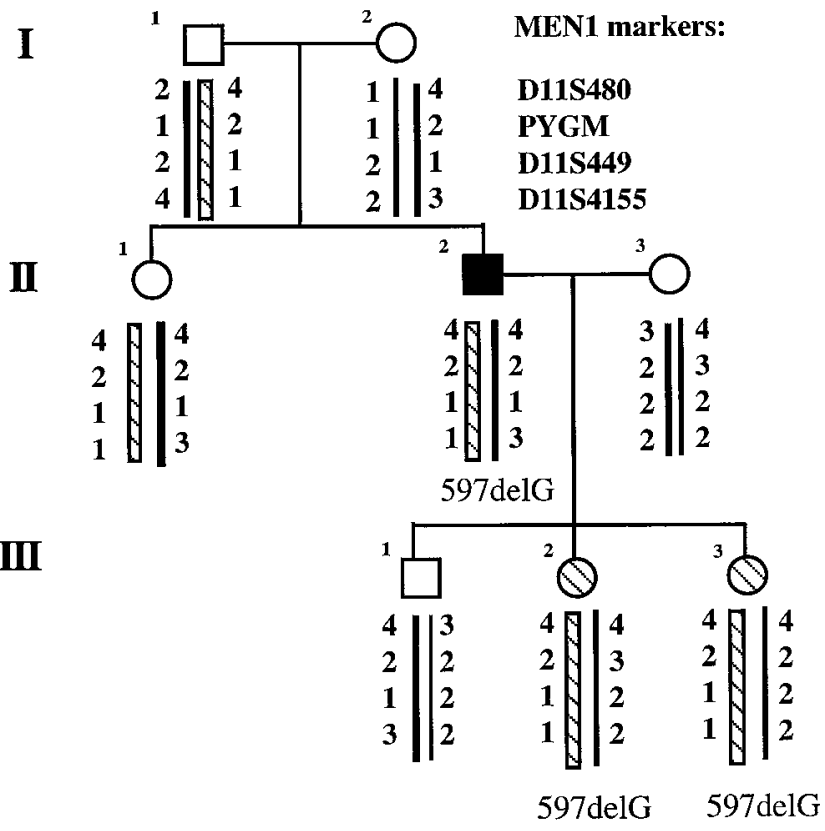

FIG. 3. A Norwegian MEN 1 patient carrying a de novo mutation, 597delG, which is not present in either parent or his sister, all of whom are clinically normal. The transmission of the mutation to his two children is compatible with that of the segregating haplotype (hatched). 
FIG. 4. Pedigree of an unreported acromegaly family of Kadazan origin (native found in Northern Borneo). All three affected cases had both physical features of acromegaly. Two were operated and the histology showed growthhormone secreting tumors. All other members were investigated clinically and biochemically without evidence of MEN 1. Haplotyping could not exclude linkage to MEN1 as the hatched haplotype was present in all affected cases. Individuals III-3 and III-4 are still in their early teens. However, from full sequencing no mutation was found.

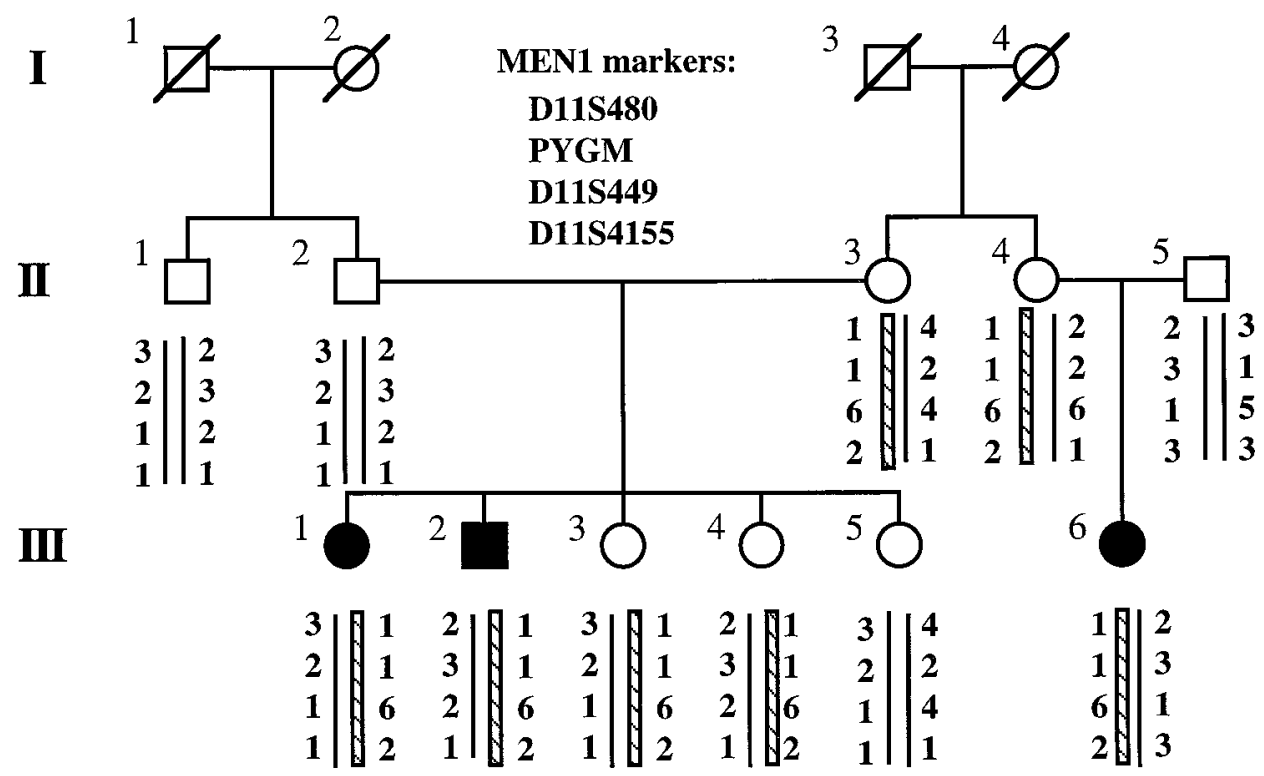

pected that new mutation rate would be similar or close to that of other populations. Here we found 2 novel different mutations in the MEN 1 kindreds: 1466del12 and D418N. At least one or more unknown mutations exist since, in 10 other cases, no mutations were identified. The 1466del12 mutation occured in 6 kindreds that shared a common 11q13 haplotype, thus pointing to a common founder in these families. The 9 familial and 1 isolated MEN 1 cases from Finland in which no mutation was detected do not share one common 11 13 haplotype and thus are not expected to have one founder mutation (23).

In agreement with previous studies (7), we did not find mutation in any of the FIHP families. These families were small or incomplete in sampling, thus haplotyping or lod score analysis were inconclusive. It is more likely that a separate gene, for example the one responsible for HPT-JT (yet to be cloned) was involved. It will be interesting to analyze some of the large FIHP families that were assigned to MEN1 (8).

As in FIHP families, we did not detect any mutation in the acromegaly families. In one family that had been excluded from MEN1 by linkage analysis (12), it was not so surprising not to find mutation in the MEN1 gene. However, one other family, shown in Fig. 4, was possibly linked to MEN1. Two siblings and one cousin developed acromegaly associated with growth hormone-secreting tumors. However, none of their parents had any feature of acromegaly, and all biochemical investigations in them were normal. It is possible that the mutations in all these families were unique and lay in regulatory or untranscribed regions of the MEN1 gene. More likely, different genetic defects other than those of the MEN1 gene might be responsible. A number of genes including G-proteins, $R b$ adenyl cyclase, and GHRH-receptor have been implicated in the pathogenesis of pituitary disease (24). It will be interesting to study the roles of these genes in these families.

In conclusion, germline mutations of the MEN1 gene are responsible for the hereditary state of MEN 1, while a num- ber of them most probably represent de novo mutation patients without a family history of the disease. Further characterization of the MEN1 mutations in parallel with functional studies, would elucidate its role both in physiological and pathological states.

\section{References}

1. Brandi ML, Marx SJ, Aurbach GD, Fitzpatrick LA. 1987 Familial multiple endocrine neoplasia type 1: A new look at pathophysiology. Endocr Rev. 8:391-405.

2. Teh BT, Hii SI, David R, et al. 1994 Multiple endocrine neoplasia type 1 in two Asian families. Hum Genet. 94:468-472.

3. Sakurai A, Katai M, Itakura Y, Nakajima K, Bab K, Hashizume K. 1996 Genetic screening in hereditary multiple endocrine neoplasia type 1: absence of a founder effect among Japanese families. Jpn J Cancer Res. 87:985-994

4. Larsson C, Skogseid B, Öberg K, Nakamura Y, Nordenskjöld N. 1988 Multiple endocrine neoplasia type 1 gene maps to chromosome 11 and is lost in insulinoma. Nature. 332:85-87.

5. Chandrasekharappa SC, Guru SC, Manickam P, et al. 1997 Positional cloning of the gene for multiple endocrine neoplasia type 1. Science. 276:404-407.

6. European Consortium on MEN. 11997 Identification of the multiple endocrine neoplasia type 1 (MEN1) gene. Hum Mol Genet. 6:1177-1183.

7. Agarwal SK, Kester MB, Debelenko LV, et al. 1997 Germline mutations of the MEN1 gene in familial multiple endocrine neoplasia type 1 and related states. Hum Mol Genet. 6:1169-1175.

8. Kassem M, Zhang X, Brask S, Eriksen EF, Mosekilde L, Kruse TA. 1994 Familial isolated primary hyperparathyroidism. Clin Endocrinol (Oxf). 41:415-420.

9. Szabo J, Heath B, Hill VM, et al. 1995 Hereditary hyperparathyroidism-jawtumor syndrome: the endocrine-tumor gene HRPT2 maps to chromosome 1q21-q31. Am J Hum Genet. 56:944-950.

10. Teh BT, Farnebo F, Kristoffersson U, et al. 1996 Autosomal dominant primary hyperparathyroidism-jaw tumor syndrome associated with renal hamartomas and cystic kidney disease: linkage to 1q21-q32 and loss of the wild-type allele in renal hamartomas. J Clin Endocrinol Metab. 81:4204-4211.

11. Benlian P, Giraud S, Lahlou N, et al. 1995 Familial acromegaly: a specific clinical entity - further evidence from the genetic study of a three-generation family. Eur J Endocrinol. 133:451-456.

12. Stock J, Warth M, Teh BT, et al. 1997 A kindred with a variant of multiple endocrine neoplasia type 1 demonstrating frequent expression of pituitary tumors but not linked to MEN1 locus at chromosome region 11q13. J Clin Endocrinol Metab. 82:486-492.

13. Yamada S, Yoshimoto K, Sano T, et al. 1997 Inactivation of the tumor suppressor gene on 11q13 in brothers with familial acrogigantism without multiple endocrine neoplasia type 1. J Clin Endocrinol Metab. 82:239-242. 
14. Pestell RG, Alford FP, Best JD. 1989 Familial acromegaly. Acta Endocrinol. 121:286-289.

15. European Consortium on MEN1.1996 Definition of the minimal MEN1 candidate area based on a 5-Mb integrated map of proximal 11q13. Genomics. 37:354-365.

15a.Lathrop GM, Laloud JM. 1994 Easy calculations of lod scores and genetic risks on small computers. Am J Hum Genet. 36:460-465.

16. Farnebo F, Teh BT, Kytölä S, et al. 1998 Alterations of the MEN1 gene in sporadic parathyroid tumors. J Clin Endocrinol Metab. 83:2627-2630.

17. Heppner C, Kester MB, Agarwal SK, et al. 1997 Somatic mutations of the MEN1 gene in parathyroid tumours. Nature Genet. 16:375-378.

18. Knudson AG. 1971 Mutation and cancer-statistical study of retinoblastoma. Proc Natl Acad Sci USA. 68:820-823.

19. Teh BT, McArdle J, Chan SP, et al. 1997 Clinicopathologic studies of thymic carcinoids in multiple endocrine neoplasia type 1. Medicine 76:21-29.

20. Teh BT, Zedenius J, Kytölä S, et al. Thymic carcinoids in multiple endocrine neoplasia type 1 . Ann Surg. In press.

21. de la Chapelle A. 1993 Disease gene mapping in isolated human populations: the example of Finland. J Med Genet. 30:857-865.

22. Hästbacka J, de la Chapelle A, Mahtani MM, et al. 1994 The disatrophic dysplasia gene encodes a novel sulfate transporter: positional cloning by fine-structure linkage disequilibrium mapping. Cell. 78:1073-1087.

23. The European Consortium on MEN. 11997 Linkage disequilibrium studies in multiple endocrine neoplasia type 1. Hum Genet. 100:657-665.

24. Shimon I, Melmed S. 1997 Pituitary tumor pathogenesis. J Clin Endocrinol Metab. 82:1675-1681. 